\title{
RAPID RESPONSE TO INTERCEPTED MUSHROOM SPAWN
}

\author{
M.K. ROMBERG, K.L. THOMAS, R.L. GRIFFIN and B.J.R. ALEXANDER \\ Investigation and Diagnostic Centre, MAF Biosecurity New Zealand, \\ PO Box 2095, Auckland 1140, New Zealand \\ Corresponding author: megan.romberg@maf.govt.nz
}

On 3 December 2008, an undeclared and mislabelled package destined for a mushroom production facility was intercepted at an Auckland courier depot. Upon X-ray and subsequent inspection, the package was found to contain two mushroom (mycelia) logs. A site investigation at the address of the intended recipients was conducted by MAFBNZ on 8 December 2008 and mushroom fruiting bodies and spawn were collected. Subsequent information determined that the unsolicited parcel was an aggressive marketing campaign by a company in China. The mushroom producer was targeted after the company's contact details were obtained from the internet. Based on the DNA sequence of the ITS region, all mushroom material from the NZ production facility was identified as Pleurotus pulmonarius, a species grown commercially in New Zealand as oyster mushrooms. The spawn intercepted at the courier depot was shown to be closely aligned to Pleurotus eryngii. In 2005, the mushroom $P$. eryngii was determined to be a new organism (Hazardous Substances and New Organism Act 1996) and unauthorised production at another mushroom facility was halted. Overseas, $P$. eryngii or king oyster mushroom is a highly prized delicacy, however, unlike most Pleurotus species, which colonise dead tissues, $P$. eryngii can grow as a parasite on living plants. No other pests or pathogens of commercial mushrooms were detected in the intercepted parcel.

\section{QUANTIFYING SURVIVAL OF NEMATODES IN DISTURBED SOIL AND UNDER PROLONGED DRYING INTERVALS}

\author{
L.T. AALDERS ${ }^{1}$, M.R. MCNEILL ${ }^{2}$ and N.L. BELL ${ }^{1}$ \\ ${ }^{1}$ AgResearch, Ruakura Research Centre, Private Bag 3123, Hamilton, New Zealand \\ ${ }^{2}$ AgResearch, Lincoln, Private Bag 4749, Christchurch 8140, New Zealand \\ Corresponding author:lee.aalders@agresearch.co.nz
}

Soil-contaminated footwear and equipment have been highlighted as a biosecurity risk for the entry of exotic unwanted organisms including nematodes into New Zealand. Exotic plant parasitic nematodes (PPN) are of concern because of the risk they pose to commercially important crops and native plants. Understanding survival probabilities of PPN in loose soil can assist in determining establishment probabilities if the soil is transported to new environments. Two experiments were carried out (spring 2008 and summer 2009) using field-collected soil to determine nematode survival after 7 , 28 and 56 days of drying under ambient conditions in the laboratory. Soil moisture at the beginning of the spring and summer experiments were ca 37 and $15 \%$ respectively. Season appeared to be an important factor in the ability of the nematodes to survive desiccation, with some plant parasitic taxa (Helicotylenchus and Criconematidae) present after 56 days in the summer experiment but none present beyond 7 days in the spring experiment. Overall, the reduction in total nematode numbers did not show a consistent pattern when compared to the day 0 samples, with a reduction of $79 \%, 83 \%$ and $97 \%$ after 7, 28 and 56 days of desiccation, respectively, for spring-collected soil and $36 \%$, $86 \%$ and $92 \%$, respectively, for summer-collected soil. 